\title{
A Case of Recurrent Massive Multinodular Parotid Pleomorphic Adenoma
}

\author{
Young Jin Loh, Hyun Gi Gim, Jong Chul Hong, and Heon Soo Park \\ Department of Otolaryngology-Head and Neck Surgery, Dong-A University College of Medicine, Busan, Korea
}

\author{
거대한 다결절성 종양으로 재발한 이하선 다형선종 1 예 \\ 노영진 · 김현기 · 홍종철 · 박헌수 \\ 동아대학교 의과대학 이비인후-두경부외과학교실
}

\author{
Received December 15, 2016 \\ Revised February 1, 2017 \\ Accepted February 10, 2017 \\ Address for correspondence \\ Heon Soo Park, MD, PhD \\ Department of Otolaryngology- \\ Head and Neck Surgery, \\ Dong-A University \\ College of Medicine, \\ 26 Daesingongwon-ro, Seo-gu, \\ Busan 49201, Korea \\ Tel $+82-51-240-5423$ \\ Fax +82-51-253-0712 \\ E-mail hspark1@dau.ac.kr
}

Pleomorphic adenoma is the most common benign neoplasm of the parotid gland and it accounts for approximately $80 \%$ of all reported tumor from parotid. Recurrence rate was noted as $20-45 \%$ and high risk factors related to recurrence were the following: over 40 years of age, women, over $30 \mathrm{~mm}$ mass size, below $10 \mathrm{~mm}$ safety margin, tumor puncture and tumor spillage during surgery, relation to the facial nerve, tumor site, surgical procedure. We experienced a 45-year-old woman who presented a huge left parotid mass. She had a huge parotid pleomorphic adenoma that was removed 18 years ago but had recurred 8 years ago. We removed the mass and obtained good postoperative results.

Korean J Otorhinolaryngol-Head Neck Surg 2018;61(8):426-9

Key Words Parotid gland · Pleomorphic adenoma $\cdot$ Recurrence.

\section{서 론}

다형선종은 타액선에서 발생하는 양성 종양 중 가장 빈도 가 높으며 이하선에 발생하는 종양의 약 $80 \%$ 를 차지한다. 주 로 중년 여성에서 호발하며, 대부분은 단일 병변으로 느린 성 장, 무통성의 종물을 특징으로 하나 주타액선 외에 여러 소 타액선에서도 발생하므로 발생 위치에 따라 다양한 증상을 나타낸다. ${ }^{1)}$

다형선종은 병리조직학적으로 양성 종양임에도 위족(pseudopodia), 위성결절(satellite nodules), 피막침윤(capsule infiltration) 등으로 표현되는 가성피막(pseudocapsule)을 가지고 있어 완전한 외과적 절제가 어려워 치료에 어려움이 많으며, 재발률은 약 20 45\%로 높다. ${ }^{2}$ 재발성 다형선종은 흔히 다발

This is an Open Access article distributed under the terms of the Creative Commons Attribution Non-Commercial License (https://creativecommons.org/licenses/by-nc/4.0) which permits unrestricted non-commercial use, distribution, and reproduction in any medium, provided the original work is properly cited.
성으로 나타나며, 악성으로 이행할 수 있고, 주변조직과 안면 신경의 유착이 심하기 때문에 재수술 시 종양의 완전제거를 위한 근치적 수술과 안경신경을 보존해야 하는 어려움이 있다. 저자들은 18년 전 수술 후 좌측 이하선에 재발한 거대한 다 발성 다형선종을 경험하였고, 안면신경의 손상 없이 제거를 하였기에 이를 보고하는 바이다.

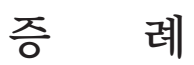

45세 베트남 여자가 약 20년 전에 발생한 좌측 이하선 종 물로 약 18년 전에 베트남에서 절제술을 받았으나, 약 8년 전 부터 종물의 재발 및 지속적인 크기의 증가로 본원에 왔다. 과거력에 특이사항은 없었으며, 신체검사에서 좌측 이하선 부위에 $9 \mathrm{~cm}$ 크기의 무통성의 고정된 단단한 종물이 촉지되 었다. 내시경 소견에서는 종물에 의한 압박으로 구인두벽이 내측으로 밀려져 있었으나, 호흡곤란 및 안면마비 등의 다른 
소견은 보이지 않았다. 경부 자기공명영상에서 인두곁공간부 터 이하선, 악하공간에 걸친 다결절성의 종물이 관찰되었고, $\mathrm{T} 2$ 강조 영상에서는 소엽화된 불균질의 고신호 강도를 보였 으며, T1 강조영상에서는 저신호 강도를 보였다. 경부 림프절 의 비대 소견은 보이지 않았다(Fig. 1A).
수술 전 시행한 미세침 세포흡입검사에서 다형선종 소견을 보였다. 저자들은 재발성 다형선종을 의심하여 좌측 이하선 전절제술을 시행하였다. 수술 중 안면신경 감시를 시행하였 으며, 이전 수술의 절개 부위를 따라 절개를 하였다(Fig. 2A). 피하에 파종 가능성은 보이지 않았으며, 안면신경을 침범한

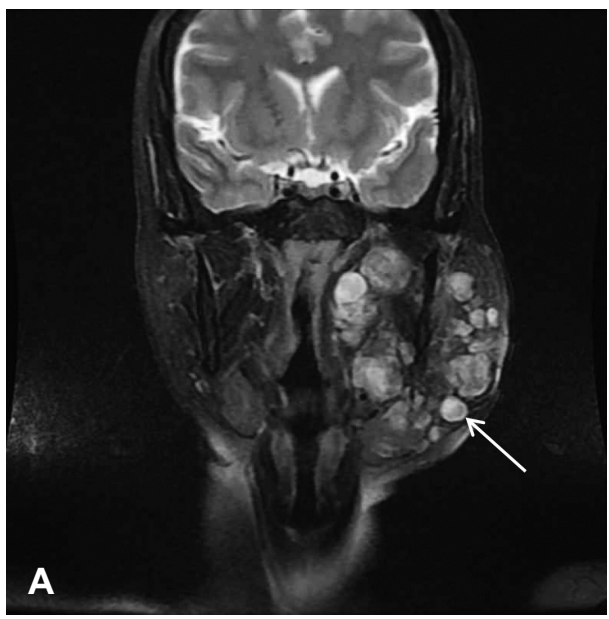

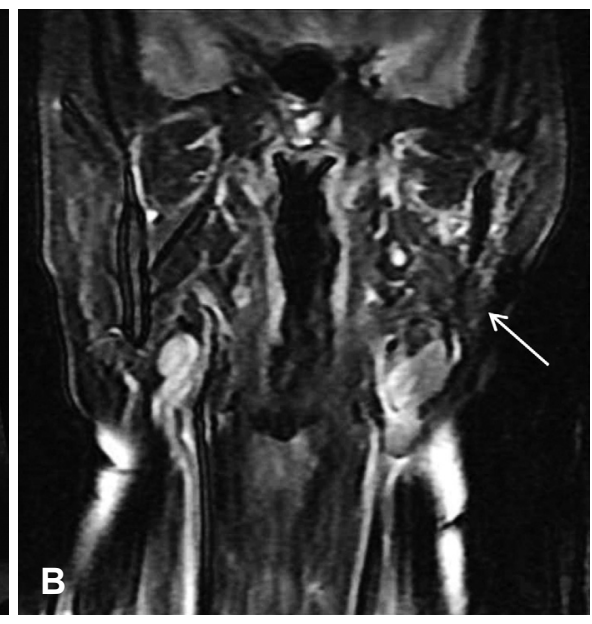

Fig. 1. Preoperative MRI findings: T2 weighted MRI shows $9 \times 10 \mathrm{~cm}$ conglomerated multinodular enhancement with irregularly shaped low attenuation lesion in parapharyngeal space and parotid gland (arrow) (A). Postoperative MRI findings: T2weighted image shows no mass between the left parotid gland and the parapharyngeal space (arrow) (B).
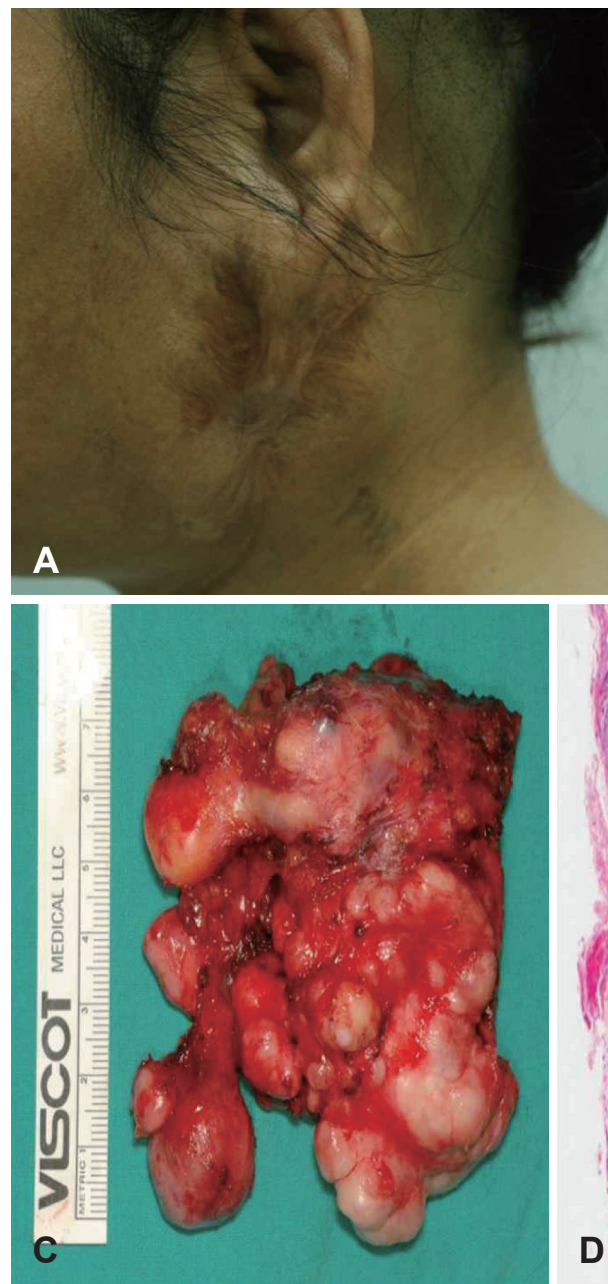
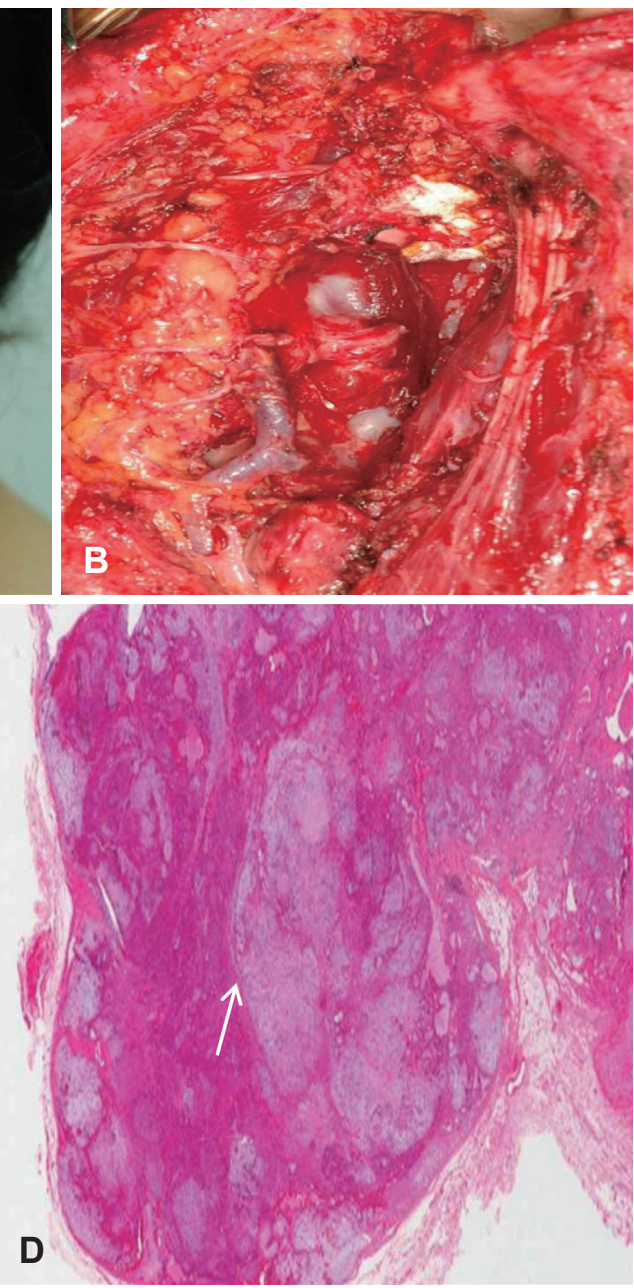

Fig. 2. A 45-year-old woman has a huge parotid mass. There is a visible postoperative scar in left neck (A). The photograph shows a pleomorphic adenoma in a deep lobe of parotid gland after a remained superficial resection of parotid gland (B). Gross pathologic specimen. The mass is $8 \times 4 \mathrm{~cm}$ in size and shows multinodular shape $(C)$. The photograph shows clear margin and thin fibrous pseudo-capsule (arrow) (H\&E, $\times 20)(D)$. 
소견도 보이지 않아 안면신경은 손상 없이 보존할 수 있었다. 거대 종물은 인두곁공간까지 확장되어 있었으나, 주위 정상 조직과의 심한 유착이나 침범은 육안적으로 보이지 않아 일 괄절제로 제거할 수 있었으며, 잔존 조직 유무를 육안으로 학 인하고 수술을 종료하였다. 제거된 종물은 약 $8 \times 4 \mathrm{~cm}$ 크기 로 국내에서 발표된 문헌 중 가장 컸다(Fig. $2 \mathrm{~B}$ and C).

수술 후에 변연하악신경 분지의 마비가 있었으나 수술 2주 후 완전 회복되었다. 병리조직검사에서 다형선종으로 나왔고 20배율의 병리 사진에서 종양은 경계가 뚜렷하고 얇으며 섬유 성의 위막은 주변과 명확히 구분되었다(Fig. 2D). 외래에서 경 과관찰 중이며 수술 2년 후 촬영한 자기공명영상에서 재발의 징후는 없다(Fig. 1B).

\section{고 찰}

이하선 다형선종은 서서히 성장하는 양성종양으로, 이하 선 종양의 $80 \%$ 를 차지하며, 천부에 호발한다. 병리조직학적 으로 피막이 형성된 회색의 종양으로, 상피세포 성분과 중배 엽성 조직이 혼재되어 있으며, 위족을 형성한다. ${ }^{1)}$

다형선종의 재발에 대한 가설에는 일차 치료 시에 위족이 불완전하게 제거되거나, 피막 손상으로 인한 종양 세포의 파종 으로 인해 발생한다는 것이 있다. 또한 우연한 종양 유출이 동반된 위막의 손상으로 재발이 발생한다는 가설도 있다. ${ }^{2)}$ 재발률은 20 45\% 내외이며 재발시기의 기간은 보통 첫 번째 수술 이후 평균 7 10년 이후 재발을 하였고, 두 번째 재발하였 을 경우 약 9년이었다. 재발간격은 단순 적출술을 시행하였을 때 현저히 짧아졌으며, 재발하였을 때는 특징적으로 $52 \%$ 가 다발성으로 재발하는 것으로 알려져 있다. ${ }^{3)}$ 저자의 증례에도 첫 수술 후 8년이 지났으며 다발성 특징이 확인되었다. 재발 과 연관된 인자들은 최초 다형선종 진단 시 40세 이상의 연 령, 여성, $30 \mathrm{~mm}$ 이상의 크기, 첫 번째 수술 시 절제된 자유연 이 $10 \mathrm{~mm}$ 이하인 경우, 수술 중 종물 손상이나 이로 인한 종 양세포의 파종이 있는 경우, 안면신경과 연관이 있는 경우, 종 물의 위치가 깊을수록 재발하는 경우가 높은 것으로 알려져 있다. ${ }^{4-6)}$ 재발의 경우에 첫 번째 수술의 범위가 종양 조절에 가장 유의하고 유일한 인자로 알려져 있다. 수술방법에 따른 재발률은 이하선 천부절제술은 1 4\%, 이하선 전절제술은 $0.4 \%$ 이하에서 재발되며 단순 적출술(enucleation)에서는 $45 \%$ 이 상 재발된다고 보고된다. ${ }^{5}$ 재발성 다형선종은 안면신경이 종 양이나 상처치유조직과 유착이 심하고 다발성 병변이 빈번하 며, 약 $10 \%$ 정도에서 악성종양으로 진행하는 경우가 있어, 종 양의 근치와 안면신경의 보존을 위한 이차 치료방법의 선택에 어려움이 많다. 이차 치료의 선택은 일차 치료의 정도와 재발
병변의 양상에 따라 결정된다. ${ }^{6}$ 재발 병변에 따라 선택 가능 한 수술의 종류는 이하선 천부절제술, 이하선 전절제술, 안면 신경의 이식을 포함한 이하선 전절제술 등이 있으며, 악성이 의심되는 경우 치료적 또는 예방적 경부절제술을 병행 가능 하다. ${ }^{\text {) }}$ 크기가 작은 병변일 경우 및 고령 또는 동반된 질환이 많을 경우 경과 관찰을 시행하며, 적출술, 피막외 절제, 이하 선 부분 절제술 후 재발한 경우에는 위치에 따라 이하선 천 부절제술 또는 이하선 전절제술을 시행하여야 한다. 이하선 천부절제술 후에 발생한 다발성 소엽성 재발의 경우 이하선 전절제술을 시행해 주어야 하며, 단일 천부에서의 재발부위 인 경우 이하선 전절제술은 필요하지 않다. ${ }^{8)}$ 저자의 증례의 경 우 재발한 큰 종양 및 위치를 고려하여 천부절제술보다는 이 하선 전절제술을 계획하였다.

술 후 방사선 치료는 술 후 상처 치유조직으로 인하여 주변 조직과 유착이 심하여 절제연이 불분명한 경우, 종양세포의 파종이 의심되는 경우, 재발 시 완전한 제거를 원할 시 사용한 다. 또한 술 후 방사선 치료는 다발성 재발환자의 국소부위 조 절에 효과가 있는 것으로 알려져 있다. ${ }^{6,9)}$ 이차 치료의 선택은 아직 여러 방법이 시행 중이지만 표준화된 치료는 아직 없다. 재발성 다형선종 수술 이후 합병증으로 안면신경마비가 가 장 흔한 것으로 알려져 있으며, 발생 위치는 안면신경의 변연 하악분지의 마비가 가장 흔하다. 여성이거나 다발성 병변인 경우, 반복적인 수술을 받았거나 이하선 심엽의 종양인 경우 발생률이 높은 것으로 되어 있다.,7) 저자들도 수술 시 안면신 경을 찾아 분지들을 모두 보존하였지만, 일시적인 변연하악 분지신경의 마비가 온 것은 신경 견인에 의해서 발생한 것으 로 생각된다.

다음으로 재발한 종양의 합병증은 악성종양으로의 변화라 고 할 수 있는데, 종양의 크기가 갑자기 커지거나 동통과 궤양 이 있을 때, 또는 안면신경마비가 동반되거나 경부 림프절 종 대가 이하선 종물과 동반된 경우에는 악성변화를 의심하여 야 한다. ${ }^{5,10)}$ 악성종양으로의 이행은 $10 \%$ 내외로 보고되고 있 으며, 주원인은 반복적인 수술이나 방사선 치료에 의한 악성 화 변성으로 생각되고 있다. ${ }^{10,11}$

수술과 방사선치료를 함께 시행한 환자군에서 종양의 국 소조절은 잘되었다는 보고는 있으나, ${ }^{6,11)}$ 아직 이에 대한 전향 적인 연구는 존재하지 않기에 앞으로 많은 연구가 필요하다. 이 환자의 경우 첫 수술 시 베트남에서 단순 적출술만 시행한 것으로 생각된다. 자유연을 포함하여 종양을 제거했기 때문 에 방사선 치료는 고려하지 않았다. 저자들은 이 증례를 통해 다형선종의 경우 첫 수술 시 충분한 자유연 확보의 중요성을 확인할 수 있었다. 


\section{REFERENCES}

1) Park YY, Shim YS, Oh KK, Lee YS, Park SJ, Kwon SU. A clinical analysis in minor salivary gland tumor. Korean J OtorhinolaryngolHead Neck Surg 1998;41(7):929-34.

2) Lee MY, Lee SJ, Kwon MS, Chung PS. Histopathologic analysis of parotid pleomorphic adenoma: resection margin and capsular characterisitcs. Korean J Otorhinolaryngol-Head Neck Surg 2009; 52(2):161-5

3) Shim YS, Yang HS. The clinic-statistical \& follow up study of nasopharyngeal malignant tumors. Korean J Otolaryngol-Head Neck Surg 1981;24(2):187-99.

4) Moonis G, Patel P, Koshkareva Y, Newman J, Loevner LA. Imaging characteristics of recurrent pleomorphic adenoma of the parotid gland. AJNR Am J Neuroradiol 2007;28(8):1532-6.

5) Riad MA, Abdel-Rahman H, Ezzat WF, Adly A, Dessouky O, Shehata $\mathrm{M}$. Variables related to recurrence of pleomorphic adenomas: outcome of parotid surgery in 182 cases. Laryngoscope 2011;121(7):1467-72.

6) Foresta E, Torroni A, Di Nardo F, de Waure C, Poscia A, Gasparini G, et al. Pleomorphic adenoma and benign parotid tumors: extracapsular dissection vs superficial parotidectomy--review of literature and meta-analysis. Oral Surg Oral Med Oral Pathol Oral Radiol 2014;117 (6):663-76.

7) Makeieff M, Pelliccia P, Letois F, Mercier G, Arnaud S, César C, et al. Recurrent pleomorphic adenoma: results of surgical treatment. Ann Surg Oncol 2010;17(12):3308-13.

8) Witt RL. The significance of the margin in parotid surgery for pleomorphic adenoma. Laryngoscope 2002;112(12):2141-54

9) Witt RL, Eisele DW, Morton RP, Nicolai P, Poorten VV, Zbären P. Etiology and management of recurrent parotid pleomorphic adenoma. Laryngoscope 2015;125(4):888-93.

10) Hwang KH, Cho HS, Kang DH, Ahn D. A case of metastasizing pleomorphic adenoma recurred as cervical lymph node metastasis after parotidectomy. Korean J Otorhinolaryngol-Head Neck Surg 2015;58(2):134-7.

11) Patel S, Mourad WF, Wang C, Dhanireddy B, Concert C, Ryniak M, et al. Postoperative radiation therapy for parotid pleomorphic adenoma with close or positive margins: treatment outcomes and toxicities. Anticancer Res 2014;34(8):4247-51. 